Print ISSN: 2234-3040 / Online ISSN 2234-3059

doi:10.13106/eajbm.2018.vol8.no2.23

\title{
Why Korean Young Women Consumers Buy Luxury Goods? The Influence of Cultural Orientation and Media Use*
}

\author{
Yuri Cha**, Yeji Kwon*** \\ Received: January 11, 2018. Revised: February 5, 2018. Accepted: April 15, 2018.
}

\section{Abstract}

Purpose - This study investigated the relationship among cultural disposition (Chemyeon, Noonchi, Woozzul), media use, and attitude toward luxury goods consumption.

Research design, data, and methodology - We analyzed online survey data for 300 Korean Women between 20 and 39 years of age who lived in Seoul, capital of South Korea. We used multiple regression analysis to examine the relative influence of cultural orientation on cognition of luxury goods, Sobel test. to determine mediating effect, and a two-way analysis of variance in IBM SPSS 23.0.

Results - The finding suggests that cultural disposition (Chemyeon, Noonchi, conspicuous Woozzul) correlated significantly with perceived self-identity, attitude toward luxury goods. The effects of Chemyeon, Noonchi, and selfish Woozzul on the attitude toward luxury goods was fully mediated by perceived self-identity. However, association between conspicuous Woozzul and attitude toward luxury goods was partially mediated by perceived self-identity. Regarding media effects, the results indicate that there were interaction effects between selfish Woozzul and amount of time spent on TV on attitude toward luxury goods, as well as between selfish Woozzul and amount of time spent on Internet.

Conclusions - These findings suggest that luxury goods consumption of Korean young women is consumer behavior that reflects individual cultural disposition and media use.

Keywords: Collectivism, Luxury Goods Consumption, Cultural Disposition, Media Use.

JEL Classifications: M30, N31, N35, M39.

\section{Introduction}

Luxury goods consumption is intertwined with a variety of areas from social relationship to product quality. Luxury goods is defined as goods that symbolize the propensity to consume and consumption capacity of individual by the use of expensive goods showing to prestige and status (Grossman \& Shapiro, 1988) or in having a traditional and classic style of handicrafts as rare at the highest quality (Shah, 2000). Hennigs et al. (2012) categorized luxury value

* This work was supported by Janghoon Fellowship Foundation in 2014.

** First Author, Institute for the Study of Media and Culture, Sogang University, South Korea.

*** Corresponding Author, Graduate School of Communication \& Arts, Yonsei University, South Korea.

Tel: +82-2-2123-3547, E-mail: yejikwon@yonsei.ac.kr into four outlined dimensions through reviewing previous studies: financial, functional, individual, and social.

The luxury goods market has been steadily increasing throughout the world. According to Euromonitor International (2016), luxury goods consumption in South Korea continued to grow in 2015. The major consumers were women, accounting for $60 \%$ of the global luxury market, while men accounted for $40 \%$ (Bain \& Company, 2013). Although the major consumers of luxury goods have traditionally been 40 to 60-year-old wealthy women, the demand for luxury goods of 20-30 year old consumers for luxury goods has sharply increased (Choi, Hong, \& Lee, 2010).

The importance placed on luxury value differs between countries although luxury values are valid across countries (Hennigs et al., 2012). Cultural orientation, especially between Eastern and Western cultures, is the influential factor in regard to luxury goods consumption. Western 
consumers tend to buy luxury goods based on individual preferences whereas Eastern consumers are inclined to pay more attention to social propriety, group pressure and face when purchasing luxury goods (Li \& Su, 2007; Wong \& Ahuvia, 1998): This is because Western culture concentrates on the 'I-identity' and individualism while Eastern culture emphasizes the 'we-identity' and collectivism (Hofstede, Hofstede, \& Minkov, 2010; Triandis, 2001). Cultural orientation is regarded as a critical factor in the cross-cultural luxury goods consumption market and is recognized as such in a number of academic disciplines (Dubois, Czellar, \& Laurent, 2005; Liao \& Wang, 2009; Yoo, Huh, \& Min, 2017). Depending on the strength of customer's cognition, purchase of goods vary (Phuong \& Dat, 2017). Therefore, this study focuses on cultural orientation in the cognition of luxury goods and its influence on luxury goods consumption.

Consumption behavior in today's media environment, which deals with advertising either directly or indirectly in most contexts, cannot be overlooked in relation to media. In South Korea, mass media which presents such as movies, magazines, and internet movies influences the trends in fashion and make-up, based on collective responses (Kim, Kim, \& Hwang, 2006). TV viewing promotes the consumption behavior of women consumers who desire to have an ideal body (Eisend \& Möller, 2007). From the younger consumer's perspective, web sites are reliable sources of information and the media thus have a direct impact on buying behavior (Calisir, 2003; Lee, Jang, \& Kim, 2012). Furthermore, the Internet is sometimes used as a maintenance space for the images of luxury goods as designers and manufacturers respond to the needs and expectations of the evolving consumers (Okonkwo, 2009).

Specifically, we examine here: (1) the relationship between the unique cultural orientation of South Koreans and the cognition of luxury goods; (2) the influence of Korean cultural orientation on the cognition of luxury goods; and (3) the impact of media usage on the cognition of luxury goods. The results of the study will help understanding the effect of the unique collectivist cultural orientation of South Koreans on luxury goods consumption and the effect of media use on the luxury goods consumption.

\section{Literature Review}

\subsection{Cultural Orientation and Attitude toward Luxury Goods}

Cultural orientations such as collectivism and individualism are related to identity and act on daily life behaviors. With collectivism, the we-identity is preferred rather than the I-identity, whereas with individualism, individual values are preferred over group values (Triandis, 1995). Collectivism aims to follow the norms and behaviors of the group and attaches importance to the relationships involved by maintaining their values and keeping their obligations (Cialdini, Wosinska, Barrett, Butner, \& Gornik-Dourose, 1999; Triandis \& Suh, 2002).

Cultural orientation influences cognition and consumption of luxury goods (Eng \& Bogaert, 2010; Souiden, M'Saad, \& Pons, 2011; Teimourpour \& Heidarzadeh Hanzaee, 2011; Xiao \& Kim, 2009). It is considered that interdependent self-identity in a collectivistic society may influence the consumption of luxury goods (Nancy \& Arron, 1998). Previous researchers, however, have not investigated sub-elements of cultural orientation in detail. Hence, in this study, an attempt is made to elaborate the cultural aspect of luxury goods consumption in an Eastern culture.

The unique factors of the cultural orientations of South Koreans such as Chemyeon (face), Noonchi (tact), and Woozzul (boasting) impact on the cognition and consumption of luxury goods in South Korea (Youm \& Lee, 2013; Youm \& Yu, 2012; Yu \& Youm, 2012). Chemyeon has a great influence on the determination of purchase behavior intention and is closely related to ritualized consumption (Lee, 1990; $\mathrm{Na}$, 1995; Sung, 1994; Yu, 2007). Chemyeon is similar to the concept of face which is "the positive social value a person effectively claims for himself by the line others assume he has taken during a particular contact (Goffman, 1955 , p.213)" or "the public self-image that every member wants to claim for himself (Brown \& Levinson, 1987, p.61)"; Chemyeon is also regarded as an individual's social status. It is closely associated with social context and is believed to show social prestige, status, wealth, and social capital (Choi \& Kim, 2000; Yang, 1994; Yu, 2007). Chemyeon in Korea, where people is extremely conscious of the way other people look at them, is even more conspicuous than politeness (Choi \& Yu, 1992). In this respect, the more people who consider Chemyeon, the more favorable are the particular brands that symbolize prestige and wealth in the social context, when recognizing and purchasing luxury products than meeting individual hedonic needs (Richins, 1994; Ting-Toomey, 1988). Li and Su (2007) showed that Chinese (Easterners) are more likely to undertake conformity face consumption, distinctive face consumption, and otheroriented face consumption than Americans (Westerners).

Noonchi meaning the process, ability, or phenomenon of identifying someone's intention through interpreting implicit, disguised or secret cues (Choi, 2000) plays a key role in attitude and toward consumption of luxury goods. South Koreans, compared to Westerners, are usually apt to explore contexts and meaning based on implicit information (Nisbett \& Masuda, 2003). Noonchi like Chemyeon is centeredrelationship so that people who are sensitive to Noonchi have positive attitude toward luxury goods consumption ( $\mathrm{Yu}$, 2007). For instance, Noonchi has a positive impact on attitude toward luxury goods through ritualized consumption 
(McCracken, 1990) which refers to the consumption behavior of expressing oneself through product or service and communicating with other people as a ritual of discovering cultural meaning in product and transferring it to the consumer (Youm \& Lee, 2013; Yu, 2007).

Woozzul refers to a conscious superiority, a conspicuous tendency, to seek admiration from others, selfishness, a sense of inferiority and self-esteem (Yeom \& Lee, 2011; Yu \& Youm, 2012). People use Woozzul to identify as better oneself than others through social comparison, to obtain people's admiration, to decrease one's inferiority, and to flaunt one's riches, power or knowledge (Yeom \& Lee, 2011). Sub-elements of Woozzul have relative influence on the cognition of luxury goods. In detail, inferiority, self-esteem, and conspicuous tendency positively affect the attitude toward luxury goods (Yu \& Youm, 2012).

Face has a partially mediating effect on the relationship between material value and brand consciousness (Liao \& Wang, 2009). Noonchi, Chemyeon, Woozzul influence attitude of luxury goods consumption through a full or partial mediation of ritualized consumption (Youm \& Lee, 2013). The mediating role of ritualized consumption to reflect the cultural value of products to oneself shows the possibility that self-identity can also play a mediating role in consumption. This is because ritualized consumption can appear as a way of expressing self-identity and cultural orientation affects the formation of self-identity. In view of this review of the literature, this study explored the following research questions.

$R Q$ 1: What is the relationship between cultural orientation and cognition of luxury goods (perceived self-identity, attitude toward luxury goods) for Korean women at 20-30's?

RQ 2: Does perceived self-identity toward luxury goods mediate the relationship between cultural orientation and attitude toward luxury goods?

\subsection{Role of Amount of Media Use from Cultivation Theory Perspective}

From cultivation theory perspective about the effect of television viewing on the perception of audiences' realistic composition (Gerbner, Gross, Signorielli, \& Morgan, 1980, 1986), mass media has ideological impacts on users (Saito, 2007). Traditionally, it has been argued that cultivation of television viewers occurs in two ways: mainstreaming and resonance. Mainstreaming means that differences found in the reactions of other viewer groups are reduced or even eliminated in the responses of heavy viewers in the same group. By monopolizing and dominating sources of information about the world, the symbolization on television makes it possible for viewers to internalize a social reality that is not an objective reality but a culturally dominant reality (Baran \& Davis, 2015). The image of material consumption has been exaggerated in Korean television programs (Yang, 2006). Amount of viewing can affect cognition of the self, and material consumption behavior (Eisend \& Möller, 2007). Especially, watching television programs have encouraged materialism (Chan, Zhang, \& Wang, 2006; Podoshen, Li, \& Zhang, 2011).

The study of the cultivation effects of television versus the new media is largely evolving into two contrasting schemes. One is that the dominance of TV network has been weakened now. When measuring the cultivation effect, it would not be appropriate to the total amount of TV viewing as an independent variable (Woo \& Dominic, 2003). There are also studies that do not emerge the cultivation effect (Perse, Ferguson, \& McLeod, 1994). On the other hand, TV is still seen as the dominant medium of past time. Internet use is considered to play a role not only in coexistence with TV viewing, but also in promoting and enhancing the TV viewing experience (Bryant \& Oliver, 2009).

Recent studies show that the magnitude of the cultivation effect of Internet use is comparable to that of television (Rhee \& Jang, 2007) or ever larger (Lee \& Han, 2013) depending on context. When it comes to luxury goods consumption, Social media marketing in the Internet has a positive effect on consumers' positive brand or product attitude, which ultimately increases the intention to buy luxury goods (Jin, 2012; Kim \& Ko, 2012). Therefore, we explored how television and the internet, the main media of modern society, affect the cognition of luxury goods in terms of the cultivation theory. In particular, this study focuses on the meaning of resonance which is the second form of cultivation induction, and addresses the possibility of interaction effect between amount of media use and cultural psychological tendency as an orientation.

We saw that the concept of resonance, the second means of cultivation, could be combined with the influence of psychological variables. Resonance occurs when real-world affairs support distorted images that are depicted on television. Consequently, it can be influenced not only by external factors relating to individuals but also by psychological factors of individuals as users and consumers which are related to their view of the world. People pay attention selectively to information of relevance to them at a particular time (Zillman \& Brayant, 1985). Moreover, the media content of a country reflects its cultural orientation (Hofstede et al., 2010). In sum, this study seeks to explore whether the amount of media use, especially television and the Internet, and cultural orientation can interact with the cognition of luxury goods.

\subsection{Snob and Bandwagon Consumption of Luxury Goods}

Unlike other cultural orientations about the cognition of 
luxury goods, selfish Woozzul of cultural orientation is likely to interact with amount of media use. Chemyeon, Noonchi and conspicuous Woozzul are common in collectivistic cultural orientation. Whereas exceptionally selfish Woozzul is conscious of the way other people but akin to the individualistic cultural orientation, as low orientation to recognize the similarities between them. The latter is rather close to snob effect if the former serves to stimulate luxury goods consumption through a bandwagon effect. This is because the bandwagon effect involves an increase in the demand for a consumer's product due to the fact that the same product is, being consumed by others; the snob effect refers to the decrease in demand for a consumer's product because of others are consuming the same products (Leibenstein, 1950). In related empirical evidence, Kastanakis and Balabanis $(2012,2014)$ indicate that consumers' vulnerability to normative influences is impacted by its dependent self as well as the bandwagon effect of luxury goods consumption behavior. The need for uniqueness is influenced by the independent self and this in turn has a significant influence on snob luxury consumption behavior.

Traditionally, collectivistic culture has been known to have different luxury goods consumption behavior from the that of Western society (Nancy \& Aaron, 1998). The symbolic meaning of a commercial brand represents cultural value and beliefs so that the unique elements of the culture are evident in Korean and American brands (Sung \& Tinkham, 2005). From this perspective, the bandwagon effect is more useful than the snob effect in understanding cognition of luxury goods by consumers because Korea is considered to be a collectivistic culture.

But aspects of individualism and collectivism can also be different in a culturally similar society (Oyserman, Coon, \& Kemmlmeiser, 2002). China is one of the representative countries in the collectivist culture (Hofstede et al., 2010), but Chinese consumers tend to have snob buying patterns rather than bandwagon because they pursue a stronger need for uniqueness than American consumers who are classified as individualists (Bian \& Forsythe, 2012). In sum, the following exploratory research question was to investigate whether the factors amount of media use and cultural orientation have an interaction effect on the cognition of luxury goods.

$R Q$ 3: Does amount of time spent on media have an interaction effect on the relationship between cultural orientation and the cognition of luxury goods?

\section{Methodology}

\subsection{Design and Sample}

A quantitative approach to the exploratory research was adopted for the current study, and data was obtained using in an online survey over eight days. We chose purposive sampling, assigning a ratio of gender and age groups to among online panels of the Invight Company. This survey was supported by 2014 Janghoon Fellowship Foundation. The valid respondents in this study were 300 living in Seoul, aging from 20 to 39 years. Although 310 participants volunteered to take the survey, 10 participants were screened out because of the amount of response time or and not fit the selection criteria.

\subsection{Demographic Variables}

The demographic variables included age, education level, and marital status. The average age of the subjects was 30.5 years (range $20-39, S D=5.10$ ) with 30 s being the most represented age group ( $58 \%$ of the sample); $42 \%$ of the sample was in the 20s. Educational level was categorized into less than high school $(18 \%, n=54)$, attended college or college graduate $(69 \%, n=207)$, and attended a graduate school or higher $(13 \%, n=39)$. Marital status was classified as currently married $(37 \%, n=111)$ or unmarried $(63 \%$, $n=189$ ). The influences of the control variables were not statistically significant.

\subsection{Measures}

\subsubsection{Cognition of Luxury goods: Dependent Measures}

The dependent variables were grouped into: (i) perceived self-identity measured with 2 items $(a=.74, r=.59, M=2.99$, $\mathrm{SD}=0.83$ ), and (ii) attitude toward luxury goods measured with 3 items $(a=.71, M=2.55, S D=0.79)$. The measures were all presented as 5-interval Likert-type scales adapted from the conception and attitude toward luxury goods literature (Park, 2010).

\subsubsection{Cultural orientation}

The cultural orientation variables were grouped into: (i) Chemyeon, (ii) Noonchi, (iii) conspicuous Woozzul, and (iv) selfish Woozzul. Using a 5-point Likert-type scale the respondents were asked to indicate how strongly they agreed or disagreed with statements made in 13 items (5 for strongly agree and 1 for strongly disagree); Chemyeon $(a=.78, M=3.23, S D=0.67)$ and Noonchi $(a=.73, M=3.12$, $\mathrm{SD}=0.73$ ) was assessed using the part of the questionnaire on 'Chemyeon' and 'Noonchi' (Yu, 2007). Woozzul was measured using a 5-point subscale as used by $\mathrm{Yu}$ and Youm (2012) and adapted from the questionnaire on 'Woozzul' (Yeom \& Lee, 2011). The three and two items from this scale had alpha reliabilities of .87 $(\mathrm{M}=2.70$, $\mathrm{SD}=0.84)$ for conspicuous Woozzul and .73 $(r=.57, \mathrm{M}=$ 2.68, $\mathrm{SD}=0.83$ ) for selfish Woozzul, respectively. A median split was used to classify who the subjects were weak or 
strong of orientation in terms of toward the media for analysis of variance.

\subsubsection{Amount of time spent on media}

The minimum time for watching TV was 0 minutes, the maximum 500 minutes. On average, participants spent 76.15 minutes $(S D=70.25)$ on watching TV (range=0-720). The average time spent on the Internet was 144.14 minutes (SD $=130.16$ ). A median split was used to classify subjects as being low or high in terms of amount of time spent with the media.

\subsection{Statistical Analyses}

A descriptive statistical study was first carried out on each of the variables. In order to verify the control variables, a bivariate correlation analysis was run with three demographic variables. None of three variables turned out to be significantly related to the cognition of luxury goods.

Next, a Pearson's product moment correlation analysis was run in order to answer the first research question (RQ1). A multiple regression analysis and Sobel test were used to determine the mediating effect in response to the $\mathrm{RQ2}$. For $\mathrm{RQ3}$ we conducted a two-way analysis of variance. A $\mathrm{p}$ value $\leqq .05$ was considered significant. Data sets were analyzed using the Statistical Package for Social Science (SPSS) 23 for Windows.

\section{Results}

\subsection{Correlations between Cultural Orientation and Cognition of Luxury Goods Variables}

Correlation analyses were carried out to explore the association between cultural orientation variables and cognition of luxury goods variables (<Table $1>)$. Cultural orientation correlated significantly with cognition of luxury goods. Notably, conspicuous Woozzul had a relatively high correlation with perceived self-identity, $r=.30, p<.001$, and correlated marginally with attitude toward luxury goods, $r=$ $.14, p<.05$.

\subsection{Mediated Effects between Cultural Orientation and Cognition of Luxury Goods}

Mediation analyses were conducted to determine whether cultural orientation variables led perceived self-identity to attitude following the steps outlined by Baron and Kenny (1986). According to Baron and Kenny, mediation may be present when three conditions are met: first, the independent variable must affect the presumed mediator, $\mathrm{XM}$; second, the independent variable affects the dependent variable, $X Y$; and third, the presumed mediator and the dependent variable are significantly related when the predictor is controlled, $B(\mathrm{YM} . \mathrm{X})$. It was found that perceived self-identity predicted attitude, $\beta=.37, \mathrm{SE}=.05, \mathrm{t}=6.86, \mathrm{p}<.001$. Moreover, cultural orientation variables were also found to predict subjects' attitude (Chemyeon: $\beta=.18, \mathrm{SE}=.05, \mathrm{t}=$ 3.10, $\mathrm{p}=.002$; Noonchi: $\beta=.12$, SE $=.05, \mathrm{t}=2.15, \mathrm{p}=$ .033 , Conspicuous Woozzul: $\beta=.30$, SE $=.05, t=5.36, p<$ .001 , Selfish Woozzul: $\beta=.15$, SE $=.05, t=2.57, p=.011$ ).

The effect of cultural orientation variables on the cognition of self-identity was statistically significant (Chemyeon: $\beta=$ $.23, \mathrm{SE}=.05, \mathrm{t}=4.16, \mathrm{p}<.001 ;$ Noonchi: $\beta=.27, \mathrm{SE}=$ $.05, \mathrm{t}=4.92, \mathrm{p}<.001$, conspicuous Woozzul: $\beta=.14$, SE $=.05, \mathrm{t}=2.50, \mathrm{p}=.013$, selfish Woozzul: $\beta=.18, \mathrm{SE}$ $=.05, \mathrm{t}=3.23, \mathrm{p}=.001$ ).

In the next model, we assessed whether perceived self-identity would mediate the relationship between the cultural orientation variables and cognition of luxury goods $(<$ Table 2>). It was found that perceived self-identity had a full mediation effect on the relationship between almost all of cultural orientation variables and attitude. Although a direct effect of conspicuous Woozzul on attitude was found, perceived self-identity only partially mediated this relationship; conspicuous Woozzul was still significant when perceived self-identity was entered as a mediator on attitude.

This estimate can be tested for significance with a Sobel (1982) test. A Sobel test confirmed that perceived self-identity mediated the relationship between the cultural orientation variables and attitude (Sobel $z=3.55, p<.001$ ), Noonchi (Sobel $z=3.97, p<.001$ ), conspicuous Woozzul (Sobel $z=2.35, p<.001$ ), selfish Woozzul (Sobel $z=2.91$, $p<.001)$ as predictors.

<Table 1> Pearson's Correlation between Cultural disposition and cognition of luxury goods

\begin{tabular}{|c|c|c|c|c|c|c|}
\hline Variable & 1 & 2 & 3 & 4 & 5 & 6 \\
\hline 1. Chemyeon & 1 & & & & & \\
\hline 2. Noonchi & $.43^{\star \star \star}$ & 1 & & & & \\
\hline 3. conspicuous Woozzul & $.33^{\star * *}$ & $.31^{* \star *}$ & 1 & & & \\
\hline 4. Selfish Woozzul & $.18^{* *}$ & $.17^{* *}$ & $.29^{\star * *}$ & 1 & & \\
\hline 5. Perceived self- identity & $.23^{\star \star *}$ & $.26^{\star * *}$ & $.14^{*}$ & $.18^{* *}$ & 1 & \\
\hline 6. Attitude toward Luxury goods & $.18^{\star \star}$ & $.12^{*}$ & $.30^{* \star *}$ & $.15^{*}$ & $.37^{\star \star \star}$ & 1 \\
\hline
\end{tabular}

Notes) ${ }^{*} p<0.05,{ }^{* *} p<0.01,{ }^{* * *} p<0.001$. 
<Table 2> Standardized Regression Weights for Predictor Variables

\begin{tabular}{|c|c|c|c|c|c|c|c|c|c|}
\hline \multirow[t]{3}{*}{ Path } & \multicolumn{5}{|c|}{ Baron and Kenny's (1986) formal test for mediation } & \multicolumn{3}{|c|}{ Sobel test } & \multirow[t]{3}{*}{ Mediation } \\
\hline & \multirow{2}{*}{$\begin{array}{c}X \rightarrow M \\
B(t)\end{array}$} & \multirow{2}{*}{$\begin{array}{l}X \rightarrow Y \\
B(t)\end{array}$} & \multicolumn{3}{|c|}{$\mathrm{X}, \mathrm{M} \rightarrow \mathrm{Y}$} & \multirow[t]{2}{*}{ z } & \multicolumn{2}{|c|}{$\mathrm{P}$} & \\
\hline & & & $\begin{array}{c}X \\
B(t)\end{array}$ & $\begin{array}{c}M \\
B(t)\end{array}$ & S.E & & $\begin{array}{l}\text { One } \\
\text {-tailed }\end{array}$ & $\begin{array}{l}\text { Two } \\
\text {-tailed }\end{array}$ & \\
\hline $\begin{array}{l}\text { Chemyeon } \\
\rightarrow \text { Perceived self- identity } \\
\rightarrow \text { Attitude toward Luxury goods }\end{array}$ & $\begin{array}{l}.23^{\star \star \star} \\
(4.16)\end{array}$ & $\begin{array}{l}.18^{\star \star} \\
(3.10)\end{array}$ & $\begin{array}{c}.10 \\
(1.73)\end{array}$ & $\begin{array}{l}.35^{\star \star \star} \\
(6.28)\end{array}$ & .05 & 3.55 & 0. 0002 & $\begin{array}{c}0 . \\
0004\end{array}$ & Full \\
\hline $\begin{array}{l}\text { Noonchi } \\
\rightarrow \text { Perceived self- identity } \\
\rightarrow \text { Attitude toward Luxury goods }\end{array}$ & $\begin{array}{l}.27^{* \star *} \\
(4.92)\end{array}$ & $\begin{array}{l}.12^{\star} \\
(2.15)\end{array}$ & $\begin{array}{c}.02 \\
(0.43)\end{array}$ & $\begin{array}{l}.36^{\star \star *} \\
(6.47)\end{array}$ & .05 & 3.97 & $\begin{array}{c}0 . \\
00004\end{array}$ & $\begin{array}{c}0 . \\
00007\end{array}$ & Full \\
\hline $\begin{array}{l}\text { Conspicuous Woozzul } \\
\rightarrow \text { Perceived self- identity } \\
\rightarrow \text { Attitude toward Luxury goods }\end{array}$ & $\begin{array}{l}.14^{*} \\
(2.50)\end{array}$ & $\begin{array}{l}.30^{\star * *} \\
(5.36)\end{array}$ & $\begin{array}{l}.25^{\star \star *} \\
(4.73)\end{array}$ & $\begin{array}{l}.33^{* * *} \\
(6.35)\end{array}$ & .05 & 2.35 & $\begin{array}{c}0 . \\
009\end{array}$ & $\begin{array}{c}0 . \\
019\end{array}$ & Partial \\
\hline $\begin{array}{l}\text { Selfish Woozzul } \\
\rightarrow \text { Perceived self- identity } \\
\rightarrow \text { Attitude toward Luxury goods }\end{array}$ & $\begin{array}{l}.18^{\star *} \\
(.32)\end{array}$ & $\begin{array}{l}.15^{*} \\
(2.57)\end{array}$ & $\begin{array}{c}.08 \\
(1.51)\end{array}$ & $\begin{array}{l}.35^{\star \star \star} \\
(6.48)\end{array}$ & .05 & 2.91 & $\begin{array}{c}0 . \\
002\end{array}$ & $\begin{array}{c}0 . \\
004\end{array}$ & Full \\
\hline
\end{tabular}

Notes) ${ }^{*} p<0.05,{ }^{* *} p<0.01,{ }^{* * *} p<0.001$.

$<$ Table 3> Interaction between Selfish Woozzul and Amount of Time Spent on Media

\begin{tabular}{|c|c|c|c|c|c|}
\hline Dependent variable & $\begin{array}{l}\text { Selfish Woozzul } \\
\text { Main effect }\end{array}$ & ATS TV & $\begin{array}{c}\text { Selfish Woozzul } \times \\
\text { ATS TV }\end{array}$ & Model & Moderation \\
\hline Perceived self- identity & $F(1,296)=5.53^{*}$ & $F(1,296)=.19$ & $F(1,296)=.16$ & $\begin{array}{c}F=1.91 \\
(d f=3,296)\end{array}$ & $x$ \\
\hline Attitude toward Luxury goods & $F(1,296)=9.37^{\star *}$ & $F(1,296)=.00$ & $F(1,296)=4.37^{*}$ & $F(3,296)=3.67^{*}$ & $\bigcirc$ \\
\hline Dependent variable & $\begin{array}{l}\text { Selfish Woozzul } \\
\text { Main effect }\end{array}$ & ATS Internet & $\begin{array}{l}\text { Selfish Woozzul } x \\
\text { ATS Internet }\end{array}$ & Model & \\
\hline Perceived self- identity & $F(1,296)=7.64^{* *}$ & $F(1,296)=.55$ & $F(1,296)=3.79+$ & $F(3,296)=3.19^{*}$ & O \\
\hline Attitude toward Luxury goods & $F(1,296)=7.59^{* *}$ & $F(1,296)=.47$ & $F(1,296)=.28$ & $F(3,296)=2.68^{*}$ & $x$ \\
\hline
\end{tabular}

Notes) $+p=.05,{ }^{*} p<.05,{ }^{* *} p<.01,{ }^{* \star *} p<.001$.

ATS $=$ Amount of Time Spent on.

\subsection{Moderated Effects of Amount of Time Spent on Media}

The results of RQ3 confirmed that strong of Noonchi participants had a positive attitude toward luxury goods $(\mathrm{M}=$ 3.01, $\mathrm{SD}=0.767$ ) compared to weak-Noonchi participants $(\mathrm{M}=2.98, \mathrm{SD}=0.884, \mathrm{~F}(1,296)=9.34, \mathrm{p}=.003)$. However, there was no significant interaction between Noonchi and the cognition of luxury goods variables.

The interaction between conspicuous Woozzul and amount of time spent on media in regard to cognition luxury goods was not statistically significant. However, as shown in $<$ Table 3>, the interaction between selfish Woozzul and amount of time spent on TV in regard to attitude toward attitude toward luxury goods was significant, $F(1,296)=$ 4.37, $p=.04$ (<Figure 1>). Moreover, selfish Woozzul and amount of time spent on the Internet emerged with a significant interaction for perceived self-identity, $F(1,296)=$ 3.79, $p=0.05$ (<Figure 2>).

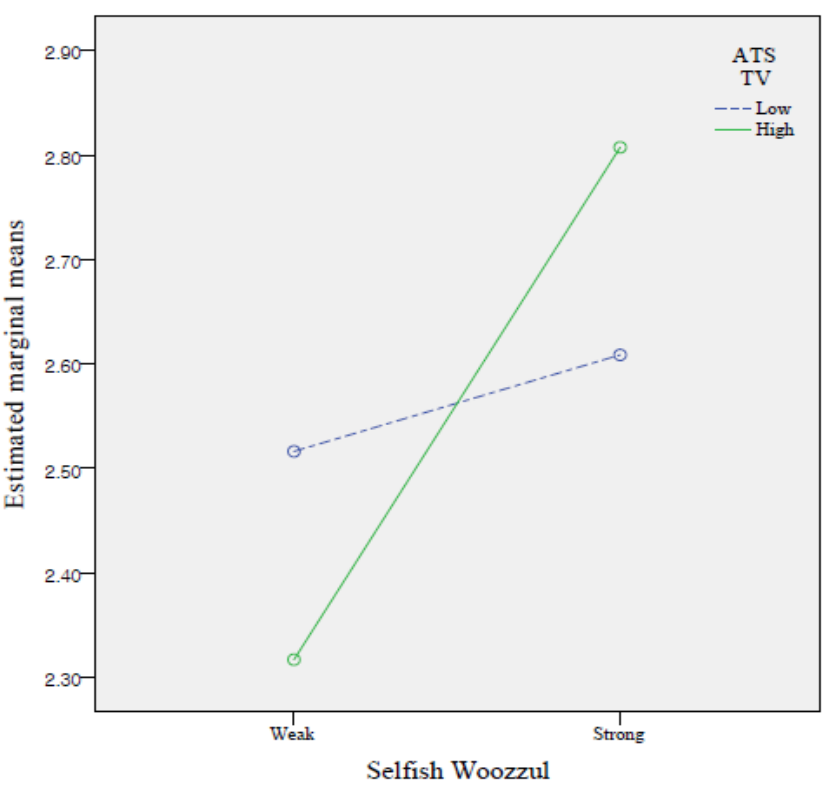

<Figure 1> On Attitude toward Luxury Goods 


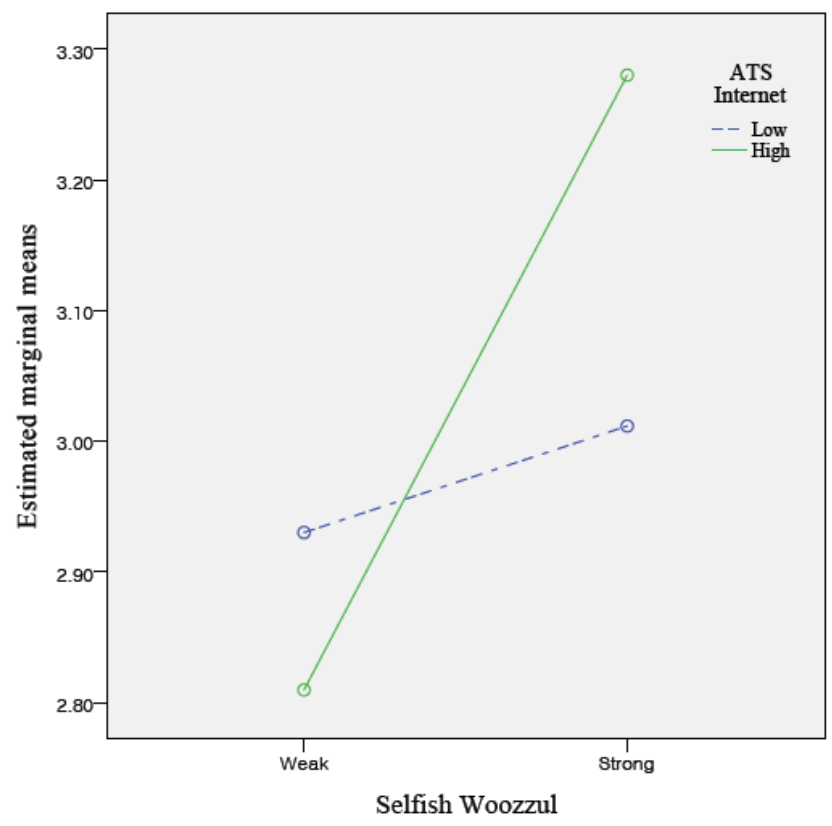

<Figure 2> On Perceived Self-identity

\section{Conclusions}

We investigated how cultural orientation and media use, especially amount of time spent on media, moderates the luxury goods consumption of Korean females at 20-30's.

In this paper, the results were as follows; (1) Chemyeon, Noonchi, conspicuous Woozzul, selfish Woozzul, perceived self-identity, attitude toward luxury goods are correlated, (2) The effects of Chemyeon, Noonchi, and selfish Woozzul on the attitude was fully mediated by perceived self-identity. However, relationship between conspicuous Woozzul and attitude was partially mediated by perceived self-identity, and (3) there were interaction effects between selfish Woozzul and Amount of Time Spent on (ATS) TV on attitude, toward luxury goods, as well as between selfish Woozzul and ATS Internet on perceived self-identity.

These findings have several theoretical and practical implications. First, this research emphasized the consumers' cultural aspect and self-identity as these embody the social value and individual value of first order latent variables. This study deals with multidimensional values. As pointed out by Wiedmann, Hennigs, and Siebels (2007), empirical studies that take multidimensional values such as financial value and functional value into account might help in-depth analysis of luxury goods consumption.

In addition, the results of the study show that individual consumption behavior is influenced by cultural orientations that affect individual's identity. This result of supports resulting of previous studies (Markus \& Kitayama, 1991; Triandis, 1995) finding that individual identity when formed by individualism or collectivism is different. It was shown that the unique cultural orientation of Koreans who belong to a collectivist culture has a positive effect on attitude and can lead to luxury goods consumption. Chemyeon, Noonchi, and Woozzul, which are focused in this study, belong to a special cultural orientation in Korea, but they are based on collectivistic culture based on group identity. Although it is consistent with the findings that collectivist cultural orientation influences individual 's conspicuous consumption in China or Japan with collectivist culture (Liao \& Wang, 2009; Xiao \& $\mathrm{Kim}, 2009)$, it is necessary to deal with cultural orientation and personal factors in future researches (Lee, 2016, Tsai, Yang, \& Lui, 2013; Xiao \& Kim, 2009).

These findings are similar to other studies what that show collectivism that consumers' self-identity in a collectivist culture can be formed by being conscious of the way other people. It is necessary to carefully examine each result of paths: Conspicuous Woozzul was the lowest among the beta values of cultural orientation influencing on perceived self-identity, and the path of conspicuous Woozzul and attitude was partially mediated by perceived self-identity. It is noteworthy that there was a small meta value and a partial mediation in this study which aimed to explore the influence of different cultural orientations on attitude toward luxury goods. Compared to Chemyeon and Noonchi, Woozzul was more conspicuous than others. From the overall results, it can be concluded that people buy luxury goods while paying attention to what other people see, we can just assume that people purchase luxury goods to 'show off'. Luxury goods consumption, in the end, takes place in the context of social relations.

On the other hand, as with young Chinese consumers categorized as collectivists who pursue a stronger need for uniqueness than U.S. consumers (Bian \& Forsythe, 2012), In the case of young Korean consumers, need for uniqueness is also likely to have an impact on their cognition toward luxury goods. It should not be overlooked that "social and cultural values reflect the core of a person's mindset, whereas consumer values are related to individual behavior during and after market transactions (Hawkins, Best, \& Coney, 2004; Xiao \& Kim, 2009, p.612)".

Thirdly, the amount of TV usage that is traditional mass media and the amount of Internet usage that is personal media for selfish Woozzul have a positive impact on attitude toward luxury goods. These results show that media usage is strongly correlated with a positive attitude, so that media releases and advertisements, whether intentionally or unintentionally, introduce new products in all content such as entertainments, drama, and documentary and stimulates consumption behavior intentions and/or purchases (Kwak, Zinkhan, \& DeLorme, 2002; Moschis \& Moore, 1982; Pooja \& Jiangmei, 2012). The interaction between the media and selfish Woozzul has a possibility of leading to a snob effect of luxury goods consumption. This is because the consumer purchases famous brand products that most people know, or 
buy luxury goods which others rarely know. Even though there is a critical difference between individualism and collectivism (Hofstede et al., 2010), we have found that people may still think individually or collectively depending on the situation.

This finding not only reaffirms the assertion of classical cultivation theory that the more television viewing, the stronger the cognition of the reality depicted by television, but also these is the implication that a similar cultivation effect occurs through Internet use in contrast to previous studies (e.g., Perse et al., 1994), and is due to the differential exposure to different content. At least, the interaction effect of the amount of Internet use time and the cultural orientation toward the cognition of luxury goods among young women consumers in South Korea is similar to results of previous studies that is the effect of extent of size of Internet use is analogous to that of television due to the tastes of media users today. Since it is the psychological orientation of the user that plays a major role in the resonance rather than the features of the medium, it seems that the patterns of interaction effect are alike. This may be a clue in support of the pessimistic view of media users, taken from traditional cultivation theory, is claiming it the media effect-oriented viewpoint may be more relevant nowadays with the shift to user-centered media.

There are several limitations that remain to be explained. While we have used cultural orientation at the social level as a factor, future research should adopt both a social level and an individual level of analysis conveying such as idiocentrism and allocentrism (Triandis \& Suh, 2002). This is because self-identity can be formed by cultural orientation and it can influence individual behavior which is evident as a result of this study. Moreover, Korea has been classified as collectivist society, a high-power distance country, a high uncertainty avoidance, long-term orientation, and feminine society by Hofstede et al. (2010) so that it is necessary for subsequent studies to take into account these other cultural orientations as major factors and be alert to reductionism errors.

Despite its limitations, this study extended our understanding of luxury goods consumption from a communication perspective, especially of Korea females by looking at luxury goods consumption in terms of cultural orientation and media use. While previous studies have only composed between collectivism and individualism, this study identified the collectivist factors of Woozzul, Chemeyon, and Noonchi and confirmed that luxury goods consumption is taking place in social relations. These findings will provide theoretical implications for those concerned with consumer behavior based upon cultural orientation, and practical implications for practitioners who sell luxury goods at a global level.

\section{References}

Bain \& Company (2013). 2013 Luxury goods worldwide market study. Retrieved January 8, 2017 from http://recursos.anuncios.com/files/581/60.pdf

Baran, S., \& Davis, D. (2015). Mass Communication Theory (7th ed.). Stamford, CT: Cengage Learning.

Baron, R. M., \& Kenny, D. A. (1986). The moderatormediator variable distinction in social psychological research. Journal of Personality and Social Psychology, 51(6), 1173-1182.

Bian, Q., \& Forsythe, S. (2012). Purchase intention for luxury brands. Journal of Business Research, 65(10), 1443-1451.

Brown, P., \& Levinson, S. C. (1987). Politeness. Cambridge, UK: Cambridge University Press.

Bryant, J., \& Oliver, M. B. (2009). Media Effects. New York, NY: Routledge/Taylor \& Francis.

Calisir, F. (2003). Web advertising vs other media. Internet Research, 13(5), 356-363.

Chan, K., Zhang, H., \& Wang, I. (2006). Materialism among adolescents in urban China. Young Consumers, 7(2), 64-77.

Choi, E., Hong, K., \& Lee, Y. (2010). Korean consumers' perceptions toward luxury products. Journal of Fashion Business, 14(5), 195-215.

Choi, S. C. (2000). Korean Psychology. Seoul, Korea: Joongang University Press.

Choi, S. C., \& Kim, K. B. (2000). The internal structure of the Korean social face (Chemyeon). Korean Journal of Social and Personality Psychology, 14(1), 185-202.

Choi, S. C., \& Yu, S. Y. (1992). Multifaceted analyses of Chemyeon (Social face). Korean Journal of Social and Personality Psychology, 6(2), 137-157.

Cialdini, R. B., Wosinska, W., Barrett, D. W., Butner, J., \& Gornik-Durose, M. (1999). Compliance with a request in two cultures. Personality and Social Psychology Bulletin, 25(10), 1242-1253.

Dubois, B., Czellar, S., \& Laurent, G. (2005). Consumer segments based on attitudes toward luxury. Marketing Letters, 16, 115-128.

Eisend, M., \& Möller, J. (2007). The influence of TV viewing on consumers' body images and related consumption behavior. Marketing Letters, 18(1-2), 101-116.

Eng, T. Y., \& Bogaert, J. (2010). Psychological and cultural insights into consumption of luxury Western brands in India. Journal of Customer Behaviour, 9(1), 55-75. 
Euromonitor International (2016). Luxury Goods in South Korea. Retrieved January 8, 2017 from http://www.euromonitor.com/luxury-goods-in-south-ko rea/report

Gerbner, G., Gross, L., Morgan, M., \& Signorielli, N. (1980). The "mainstreaming" of America. Journal of Communication, 30(3), 10-29.

Gerbner, G., Gross, L., Morgan, M., \& Signorielli, N. (1986). Living with television. In J. Bryant \& D. Zillman (Eds.), Perspectives on media effects (pp. 17-40). Hillsdale, NJ: Erlbaum.

Goffman, E. (1955). On face-work. Psychiatry, 18 (August), 213-231.

Grossman, G. M., \& Shapiro, C. (1988). Foreign counterfeiting of status goods. Quarterly Journal of Economics, 103(1), 79-100.

Hawkins, D. I., Best, R. J., \& Coney, K. A. (2004). Consumer Behavior (9th ed.). New York, NY: Irwin-MGraw Hill.

Hennigs, N., Wiedmann, K. P., Klarmann, C., Strehlau, S., Godey, B., \& Pederzoli, D., et al. (2012). What is the value of luxury? A cross-cultural consumer perspective. Psychology \& Marketing, 29(12), 1018-1034.

Hofstede, G., Hofstede, G. J., \& Minkov, M. (2010). Cultures and Organizations. London, UK: McGraw-Hill.

Jin, S. A. A. (2012). The potential of social media for luxury brand management. Marketing Intelligence \& Planning, 30(7), 687-699.

Kastanakis, M. N., \& Balabanis, G. (2012). Between the mass and the class. Journal of Business Research, 65(10), 1399-1407.

Kastanakis, M. N., \& Balabanis, G. (2014). Explaining variation in conspicuous luxury consumption. Journal of Business Research, 67(10), 2147-2154.

Kim, A. J., \& Ko, E. (2012). Do social media marketing activities enhance customer equity? An empirical study of luxury fashion brand. Journal of Business Research, 65(10), 1480-1486.

Kim, Y., Kim, M., \& Hwang, J. (2006). The effect of mass media on fashion leadership of make-up and fashion products. Journal of the Korean Society of Clothing and Textiles, 30(2), 266-274.

Kwak, H., Zinkhan, G. M., \& DeLorme, D. E. (2002). Effects of compulsive buying tendencies on attitudes toward advertising. Journal of Current Issues \& Research in Advertising, 24(2), 17-32.

Lee, C. (1990). Modifying an American consumer behavior model for consumers in Confucian culture. Journal of International Consumer Marketing, 3(1), 27-50.
Lee, H. S. (2016). Do ethical consumers really love green brand?. Journal of Distribution Science, 14(2), 23-30.

Lee, K. K., Jang, S. N., \& Kim, P. J. (2012). Research on Purchase Decision Factors to TV Home Shopping Product. The East Asian Journal of Business Management, 2(2), 13-21.

Lee, S. J., \& Han, E. K. (2013). Media use and consumption values. The Korean Journal of Advertising, 24(8). 257-275.

Leibenstein, H. (1950). Bandwagon, snob, and Veblen effects in the theory of consumers' demand. The Quarterly Journal of Economics, 64(2), 183-207.

Li, J. J., \& Su, C. (2007). How face influences consumption. International Journal of Market Research, 49(2), 237-256.

Liao, J., \& Wang, L. (2009). Face as a mediator of the relationship between material value and brand consciousness. Psychology \& Marketing, 26(11), 987-1001.

Markus, H. R., \& Kitayama, S. (1991). Culture and the self. Psychological Review, 98(2), 224-253.

McCracken, G. (1990). Culture and Consumption. Minneapolism, MN: Indiana University Press.

Moschis, G. P., \& Moore, R. L. (1982). A longitudinal study of television advertising effects. Journal of Consumer Research, 9(3), 279-286.

$\mathrm{Na}$, E. Y. (1995). Cultural impediments in mind reformation. Korean Journal of Psychology: Social Issues, 2(1), 33-51.

Nancy, Y. W., \& Aaron, C. A. (1998). Personal taste and family face. Psychology \& Marketing, 15(5), 423-441.

Nisbett, R. E., \& Masuda, T. (2003). Culture and point of view. Proceedings of the National Academy of Sciences, 100(19), 11163-11170.

Okonkwo, U. (2009). Sustaining the luxury brand on the Internet. Journal of Brand Management, 16(5-6), 302-310.

Oyserman, D., Coon, H. M., \& Kemmelmeier, M. (2002). Rethinking individualism and collectivism. Psychological Bulletin, 128, 3-72.

Park, J. (2010). A study on Korean and Japanese consumers' attitudes and consumer knowledge about luxury brands. Journal of the Korean Society of Clothing and Textiles, 34(8), 1303-1318.

Perse, E. M., Ferguson, D. A., \& McLeod, D. M. (1994). Cultivation in the newer media environment. Communication Research, 21(1), 79-104.

Phuong, N. N. D., \& Dat, N. T. (2017). The Effect of Country-of-Origin on Customer Purchase Intention. The Journal of Asian Finance, Economics and 
Business, 4(3), 75-83.

Podoshen, J. S., Li, L., \& Zhang, J. (2011). Materialism and conspicuous consumption in China. International Journal of Consumer Studies, 35(1), 17-25.

Pooja, M., \& Jiangmei, C. (2012). The impact of social media usage on consumer buying behavior. Advances in Management, 5(1), 14-22.

Rhee, J. W., \& Jang, H. M. (2007). Cultivation on the Internet. Korean Journal of Journalism \& Communication Studies, 51(2), 363-391.

Richins, M. L. (1994). Valuing things. Journal of Consumer Research, 21, 503-521.

Saito, S. (2007). Television and the cultivation of gender-role attitudes in Japan. Journal of Communication, 57(3), 511-531.

Shah, D. (2000). A new definition luxury. Textile View, 52, 6-7.

Sobel, M. E. (1982). Asymptotic confidence intervals for indirect effects in structural equation models. Sociological Methodology, 13, 290-312.

Souiden, N., M'Saad, B., \& Pons, F. (2011). A cross-cultural analysis of consumers' conspicuous consumption of branded fashion accessories. Journal of International Consumer Marketing, 23(5), 329-343.

Sung, Y. S. (1994). Materialism and types of ostentation consumption. Korean Journal of Psychology: Social Issues, 1(1), 69-82.

Sung, Y., \& Tinkham, S. F. (2005). Brand personality structures in the United States and Korea. Journal of Consumer Psychology, 15(4), 334-350.

Teimourpour, B., \& Heidarzadeh Hanzaee, K. (2011). The impact of culture on luxury consumption behaviour among Iranian consumers. Journal of Islamic Marketing, 2(3), 309-328.

Ting-Toomey, S. (1988). Intercultural conflict styles. In Y. Y. Kim \& W. B. Gudykunst (Eds.), Theories in Intercultural Communication (pp.212-235). Newbury Park, CA: Sage.

Triandis, H. (1995). Individualism and Collectivism. Boulder, CO: Westview Press.

Triandis, H. (2001). Individualism-collectivism and personality. Journal of Personality, 69(6), 907-924.

Triandis, H. C., \& Suh, E. M. (2002). Cultural influences on personality. Annual Review of Psychology, 53(1), 133-160.

Tsai, W. S., Yang, Q., \& Liu, Y. (2013). Young Chinese consumers' snob and bandwagon luxury consumption preferences. Journal of International Consumer Marketing, 25(5), 290-304.
Wiedmann, K. P., Hennigs, N., \& Siebels, A. (2007). Measuring consumers' luxury value perception. Academy of Marketing Science Review, 2007, 1-22.

Wong, N. Y., \& Ahuvia, A. C. (1998). Personal taste and family face. Psychology \& Marketing, 15(5), 423-441.

Woo, H. J., \& Dominick, J. R. (2003). Acculturation, cultivation, and daytime TV talk shows. Journalism \& Mass Communication Quarterly, 80(1), 109-127.

Xiao, G., \& Kim, J. O. (2009). The investigation of Chinese consumer values, consumption values, life satisfaction, and consumption behaviors. Psychology \& Marketing, 26(7), 610-624.

Yang, H. (2006). The effects of viewing entertainment programs on material values and feelings of relative deprivation. Korean Journal of Broadcasting and Telecommunication Studies, 20(4), 121-155.

Yang, M. M. (1994). Gifts, Favors, And Banquets. Ithaca, NY: Cornell University Press.

Yeom, D. S., \& Lee, C. Y. (2011). Factor analysis of Korean consumer's propensity and ritualism and their influences on attitudes toward the luxury brand advertising. Journal of Korea Society of Design Forum, 33, 451-460.

Yoo, S. S., Huh, M. Y., \& Min, K. D. (2017). Women as Consumers. The Journal of Industrial Distribution \& Business, 8(7), 31-38.

Youm, D., \& Yu, S. (2012). A study of consumption behavior of Korea consumers of luxury goods. Korean Journal of Consumer and Advertising Psychology. 13(3), 323-341.

Youm, D. S., \& Lee, C. Y. (2013). Causal analysis of the effect of Koreans' socio-psychological characteristics and ritualized consumption on their attitude of luxury goods consumption. Korean Journal of Consumer and Advertising Psychology, 14(2), 269-293.

Yu, S. Y. (2007). Cultural psychological factors on ritualized consumption in Korean. Korean Journal of Consumer and Advertising Psychology, 8(2), 205-233.

Yu, S. Y., \& Youm, D. S. (2012). The impact on the Korea Characteristic influence on the attitude of luxury product. Journal of Digital Convergence, 10(1), 203-213.

Zillmann, D., \& Bryant, J. (1985). Selective Exposure to Communication (Eds.). Hillsdale, NJ: Lawrence Erlbaum. 